\title{
MISS BETTY PIKE
}

Editor of The Aeronautical Quarterly from 1953 to the end of 1977, Miss E.C. Pike, is retiring from the staff of the Society. It has been largely due to her efforts that the Quarterly has continued so successfully through a difficult period of steeply rising costs.

Betty Pike went to Somerville College, Oxford, in 1937 to read Mathematics, and in 1941 she joined the Technical Office of Vickers-Armstrongs (Supermarine) Ltd and worked on aerodynamics and performance calculations and flight test reduction. In 1946 she joined the staff of the Society and was at first concerned mainly with Performance Data Sheets. She became an Associate Fellow in January 1947. In later years, in addition to her work for The Aeronautical Quarterly, she was secretary to the Medals and Awards Committee and to the Agricultural Aviation and Man-Powered Aircraft Groups. She also edited the Society's monographs and book reviews.

In 1971 The Aeronautical Quarterly was in difficulties. Costs were rising and the long delay between submission of a paper and publication was discouraging authors. Betty tackled both these problems energetically, introducing new methods of reproduction with greatly reduced costs and cutting down the delay in publication. The Quarterly in its new form became popular with authors and its future now seems assured. Throughout the period of her editorship Betty's knowledge and understanding of authors and referees has been invaluable. She was elected to Fellowship in 1975.

Betty is a keen golfer and during the late 1940's and early 1950's she played cricket for Middlesex, including a spell as captain, and for the South of England as a wicket keeper and a forceful middle order batsman. She was also involved in the administrative side of the game. She will be living in Scotland after she retires but will not lose touch with the Society. Her many friends at the RAeS wish her good health and happiness in her retirement.

\author{
W, A. MAIR \\ Chairman, Editorial Board.
}

